\title{
'Please' as an impoliteness marker in English discourse
}

\author{
Laya Heidari Darani a (D), Mostafa Morady Moghaddam b * \\ a Department of English, Falavarjan Branch, Islamic Azad University, Isfahan, Iran \\ ${ }^{b}$ Department of English, Shahrood University of Technology, Shahrood, Iran
}

\begin{tabular}{l|l|l} 
Received 19 March 2020 & Received in revised form 4 July 2020 & Accepted 4 July 2020
\end{tabular}

\section{APA Citation:}

Heidari Darani, L., \& Moghaddam, M. M. (2020). 'Please' as an impoliteness marker in English discourse. Eurasian Journal of Applied Linguistics, 6(2), 243-263.

Doi: $10.32601 /$ ejal.775805

\begin{abstract}
This study explored how Iranian EFL learners and native English speakers conceptualized the impolite use of please in interaction. Moreover, attempts were made to examine whether Iranian EFL learners and native English speakers differ in using the impolite version of please in their communications. To this end, informal conversations of 20 Iranian EFL learners in pairs and small groups were recorded and transcribed. The impolite version of please in these conversations was compared with similar data from the Bergen Corpus of London Teenage Language (COLT). According to results, several functions of the 'impolite' please were found among Iranian EFL learners and native English speakers. Firstly, please was used to establish or confirm harmonious relationships between the speakers; it was used as rapportstrengthening impoliteness marker. Secondly, 'mock impoliteness' was conceptualized to bear positive meaning since it was interpreted as an amusing or entertaining remark. In teenagers' circles, entertainment skills whereby impolite please was employed were highly valued. Thirdly, participants adhered to 'repetition', 'reformulation', and 'escalation' in their interactions to show their creative impoliteness. Finally, it was concluded that certain functions of the impolite please were shared between the Iranian EFL learners and native English speakers, while some functions were not shared between these two groups.
\end{abstract}

(C) 2020 EJAL \& the Authors. Published by Eurasian Journal of Applied Linguistics (EJAL). This is an open-access article distributed under the terms and conditions of the Creative Commons Attribution license (CC BY-NC-ND) (http://creativecommons.org/licenses/by-nc-nd/4.0/).

Keywords: impoliteness; Iranian EFL learners; native English speakers; please; politeness; pragmatics.

\section{Introduction}

Politeness and impoliteness are somewhat underdeveloped areas of investigation in intercultural communication (but see Culpeper, Haugh, \& Kádár, 2017 for more information). This is because for many researchers, (e.g., Brown \& Levinson, 1987; Kecskes, 2017; Lakoff, 1973) politeness and impoliteness are universal concepts that are represented differently in languages through a variety of lexical items and

\footnotetext{
* Corresponding author. Tel.: +98-938-745-0746

E-mail address: heidari@iaufala.ac.ir

mmoghaddam@shahroodut.ac.ir

http://dx.doi.org/10.32601/ejal.775805
} 
structures. To Lakoff (1975), politeness is formed in society to alleviate discrepancies. Politeness is an indispensable part of communication and its significance in communication is relevant to concepts such as truthfulness, informativeness, relevance, and clearness (Brown \& Levinson, 1978; Grice, 1975; Leech, 1983). Impoliteness is defined (Tracy \& Tracy, 1998, p. 227) as "communicative acts perceived by members of a social community (and often intended by speakers) to be purposefully offensive." Then, given the role of the speaker and hearer, Culpeper (2005, p. 38) refers to impoliteness as the contexts where "(1) the speaker communicates face-attack intentionally, or (2) the hearer perceives and/or constructs behavior as intentionally face-attacking, or a combination of (1) and (2)."

Brown and Levinson's $(1978,1987)$ classic work has been the backbone of many studies done on politeness up to now (Eelen, 2001; Van der Bom \& Mills, 2015). Most studies regarding Brown and Levinson's work have aligned to an antagonist view (for example, Arundale, 2006; Eelen, 2001; Mullany, 2006; Watts, 2003). In the same vein, Culpeper (2005) proposed a model of impoliteness that is, in essence, the counterpart of the model of politeness put forward by Brown and Levinson (1987). Both assert that a positive relationship can be found between impoliteness and power difference between the speaker and the hearer. Brown and Levinson's (1987) theory does not admit impoliteness strategies or strategies which are neither polite nor impolite. Culpeper's work (2005) is in contradiction to Leech's perspective $(1983,2007)$ such that he maintains that impoliteness is not inherent and the speech context is responsible for any impolite act. Later, certain types of behavior, including nonintentional impoliteness, incidental threats, banter, and politeness without redressive action were removed from Culpeper's taxonomy, whereas sarcastic off record impoliteness was added as a new category of impoliteness (Culpeper, 2005).

Politeness is an essential part of every natural language, and, in conversation, we constantly make choices about where and how to use devices to manage politeness. Indeed, a close relationship is perceived between politeness markers and power relations in social interactions, and this relationship is a decisive factor showing how well the interactions proceed (Andersson \& Pearson, 1999; Chilton, 1990; Gyasi Obeng, 1997; Holmes, Marra, \& Vine, 2012; Holmes \& Stubbe, 2005; Rogers \& LeeWong, 2003). Watts (2003) holds that native speakers of languages use politeness markers or structures such as hedges (e.g., 'sort of,' 'kind of,' 'rather'), intensifiers, politeness markers (e.g., 'please'), and committers as 'linguistic expressions' (p. 182) to signal politeness. They employ these markers/structures to lessen the amount of imposition on the addressee (Watts, 2003).

This study is motivated to find out how Iranian EFL learners use the term 'please', and which functions are behind the application of 'please'. In addition, attempts are made to explore the differences between Iranian EFL learners and native English speakers in the use of this politeness marker. Thus, this article aims to probe whether 'please' can be used to show impoliteness for speakers of different languages where English is taught and learned as a foreign language. 
The objective of the present study is to explore the structures co-occurring with the term 'please' and the impolite functions of 'please'. The term 'please' can also serve as an impoliteness function by native English speakers and it is intended to examine whether the same pattern is followed by Iranian EFL learners. In the following section (Section 2), some notes on the term 'please' are presented. Reviewing the theoretical and empirical studies conducted on the term 'please' is done in Section 3. We deal with briefing the current study in Section 4. Methodology, including the subjects participated in this study, and data collection procedure is explained in Section 5. Results of the study as well as the findings pertaining to native English speakers' data are reported in Section 6. Discussing the findings and comparisons and conclusions are presented in Sections 7 and 8, respectively.

\subsection{Some notes on the term 'please'}

Several scholars have paid attention to the word please (Fraser, 1996; House, 1989; Sato, 2008; Wichmann, 2004) which is assumed to be used frequently to express politeness in English discourse. Fraser (1996) mentions that "[w]hen please occurs before an imperative structure, it signals that the speaker intends the utterance to be taken as a request, and only as a request" (Fraser, 1996, p. 174). Aijmer (2009) also refers to the concept of politeness that is expressed through the word 'please' in addition to the illocutionary force. However, Wichmann (2004, p. 1524) asserts that "the word please in contemporary usage is [...] undeniably associated very closely with being 'polite'." Thus, it can be inferred that please occurs "with a varying degree of politeness and directive force" (Sato, 2008, p. 1250).

Markers such as please that are connected to requests (especially the imperative) and politeness (e.g., German bitte, French s'il vous plait, Persian lotfan) can be found in several languages. An overview of the previous research suggests that there have been two predominant views held toward the functions of please. The lexical item please is characterized either as a politeness marker whose focus is on the addressee (Blum-Kulka \& Levenston, 1987; Dalton-Puffer, 2005; Economidou-Kogetsidis, 2005; Ervin-Tripp, 1982; Faerch \& Kasper, 1989; House \& Kasper, 1981; Leech \& Svartvik, 1975; Lwanga-Lumu, 2002; Stubbs, 1983; Trosborg, 1995) or as a request marker (Brownell \& Stringfellow, 1999; House, 1989; Wichmann, 2004). Concerning the first view, please is first and foremost a lexical downgrader, the function of which is to mitigate the face-threatening content transferred by request and/or by the imperative. Please is confirmed to be used in requests, and it is widely accepted that it is a thoroughly ritualized formulaic expression (Gleason, Perlmann, \& Greif, 1984; Watts, 2003); hence, this has led to the determination of please as a request marker.

The meaning associated with please depends on the sentence type. A variety of sentences can have please embedded in them (declaratives, interrogatives, imperatives). It can also stand freely without the need to be inserted into a sentence. Please, either inserted into sentences or isolated, is accompanied by a directive (Wichmann, 2004). Directives are formed as an imperative, which can be 
distinguished from (indirect) requests. Interrogative sentences, modal interrogatives (can you, could you), declaratives with modals ( $I$ can) and elliptical constructions are the structure types usually used to denote indirect requests. Moreover, please can occur in isolation (e.g., yes please and no please) (Aijmer, 2015).

In Persian, commands and indirect requests are made using the Persian equivalent of please (i.e., 'lotfan'). Indirect requests include modal interrogatives with mishelmitoonam (translated in English as 'can you', 'can I') and commands include imperatives (Taleghani-Nikazm, 2011). Comparing Persian with English, three utterance types are missing in Persian: declaratives with modals, elliptical constructions, and free-standing please.

\section{Review of the literature}

Brown and Levinson's (1987) theory of politeness is grounded in Goffman's notion of 'face', both positive and negative. Social interaction is regarded as successful if speakers focus their attention on the addressee's negative and positive face. Face is always vulnerable. The issue is how threatening behaviour is perceived to be. As stated by Wichmann (2004), 'request' is a speech act that may probably threaten an addressee's face. This threat depends on certain social factors such as the addressee's culture. Thus, politeness necessitates language speakers to attenuate their request. To mitigate the request, the most widely used strategy in English is to present an indirect request, usually done through a modal question.

Although there are restrictions on the use of please, it gives the impression that it is resistant to be functionally categorized. In the same way as the rest of the grammaticalized items, please seems not to carry propositional meaning anymore; instead, it acts to 'facilitate the ongoing interaction' (Biber, Johansson, Leech, Conrad, \& Finegan, 1999, p. 140). Indeed, during conversations that are interactive, the meaning is given to these items and thus express 'politeness, emotion and attitude' (Biber et al., 1999, p. 1047).

A plethora of empirical studies has been conducted on politeness and the term 'please' as a politeness marker related to English discourses. In their 1989 study, Faerch and Kasper compared the requests made by Danish learners of English and German with those made by native speakers of these two languages. The findings indicated that downtoners (e.g., 'possibly') were underutilized, while the politeness marker 'please' was overutilized by learners in both English and German. The authors maintained that politeness markers were well-favored by learners and this is because it has a "double function as illocutionary force indicator and transparent mitigator" (Faerch \& Kasper, 1989, p. 232). Further, learners need lower degrees of pragmalinguistic competence while using politeness markers than downtoners, and this may be the reason why learners used downtoners to a smaller extent.

Martínez-Flor (2009) referred to the word 'please' as one of the most widely used modifiers to attenuate the imposition inherent in requests. Regardless of requests which have the main function, the use of 'please' in other functions, including making 
a directive or focusing on speakers' speech, was not investigated sufficiently. Thus, this study probed the use and function of please used in requests made by Spanish EFL learners in unplanned oral tasks. The findings showed that i) please is one of the commonly used modifiers learners use in their requests, ii) its main use is the attenuation function, and iii) it always has a final position in the request move.

The concept of 'please' has been studied in languages other than English as well. Barron's studies (2000, 2003), which dealt with Irish learners of German who had spent a year abroad studying in Germany and two groups of native speakers of both languages, also showed the same developmental pattern. In the beginning, in line with Faerch and Kasper's (1989) and Hill's (1997) studies, downtoners were underutilized and the politeness marker 'please' was over-utilized by learners. She observed a remarkable change in patterns over time, where an inclination and a decline were observed respectively in the use of downtoners and 'please'. In addition, as far as the position of 'please' was concerned, it was found that learners approached the native speakers' norms by inserting it in an embedded position, which also represented development in their pragmatic competence.

Bernal (2008) explored authentic and non-authentic politeness among Spanish speakers. It is interesting as it is concerned with another language than English. It was found that some expressions whose intention was to mock or insult the interlocutor may carry "an affiliative social effect, strengthening feelings of solidarity within a group and of closeness between interlocutors" (2008, p. 781). In this study, certain expressions in Peninsular Spanish which had impolite effects (genuine impoliteness) as well as those expressions implying "apparent impoliteness only" (non-authentic impoliteness) were explored (Bernal, 2008, p. 782). He also focused on the interpretations made by the hearers as to how "impoliteness can be entertaining" (p. 782). As a result, we can assume that a variety of languages, Spanish included, may use inherently polite expressions in an impolite manner for mock impoliteness or banter purposes.

An exception to the previous studies is De Felice and Murphy (2015, p. 87) who allude to please with implied rudeness (particularly in American English): "However, some informal claims have been made [...] that the presence of please requests can seem less polite in American English than the equivalent request without it, emphasizing social power differences and expressing impatience." The pragmatic constraint of please with a 'request' has led researchers to investigate the use of please in various requestive environments, many of which resulted in comparative studies in a variety of cultures and speech communities (e.g., Economidou-Kogetsidis, 2005; House, 1989; Lee-Wong, 1994; Markkanen, 1985; Yamazaki, 2002).

Recently, we have witnessed the publication of many books and articles (Bousfield, 2008; Bousfield \& Locher, 2008; Culpeper, 2005, 2011; Haugh, 2007, 2011; Kecskes, 2017; Kienpointner, 1997; Níkleva, 2018) about impoliteness. However, to our best knowledge, we found out that no study has been conducted to explore the use of please accompanied by impoliteness structures in the EFL context. Thus, this study made an 
attempt to identify the use of please among Iranian EFL learners' interactions and the functions of please-accompanied structures. In addition, it was explored whether please is used differently by Iranian EFL learners and native English speakers.

\subsection{Current study}

Andersen (2001) studied the use of pragmatic markers such as 'like' produced by teenagers in situations which were strange for those who did not belong to their group. He suggests that "more generally, it is of interest to investigate whether adolescence and adulthood are essentially different with respect to interactional and politeness principles" (Andersen, 2001, p. 307). In comparison to adults, teenagers presumably focus less attention on politeness and phatic expressions; in addition, their interruptions are more, and they mostly co-occur with 'mock insults'. Inspired by Andersen's study (2001), the present work aimed at probing how Iranian teenage EFL learners and native English teenage speakers draw on please in their interactions and what functions exist behind the structures in which please is used. Moreover, attempts are made to explore whether Iranian teenage EFL learners and native English teenage speakers differ in using please in their interactions. The findings of this study may reveal that teenagers behave differently from adults as far as language is concerned even in their friendly interactionism, and thus specific $\mathrm{im} /$ politeness markers can probably be used inversely. This highlights the fact that adults are required to be aware of this difference and the teenagers' rude language accompanied by politeness marker please does not indicate impoliteness among their same-age mates; instead, it is an indicator of their rapport and is not considered as threatening, like what we experience among adults. The results could contribute to the universal nature of politeness/impoliteness put forward by Brown and Levinson (1987) and Lakoff (1975). Furthermore, when please is accompanied by an impolite structure, the hearer's face-threatening is tried to be lessened, and thus Brown and Levinson's politeness (1987) theory is strengthened. As Culpeper (2005) claimed, an impolite structure can come along with please to exclude it from the impoliteness taxonomy.

\section{Method}

This study followed a mixed-methods design in which the frequency of utterance types co-occurring with please made by Iranian teenage EFL learners and native English speakers were determined. This qualitative study was followed by the analysis of the utterances to identify the functions of please.

\subsection{Subjects}

The subjects of this study comprised eight male and 12 female Iranian teenage EFL learners whose ages ranged between 18 and 19. They were native speakers of Persian who studied English at the department of foreign languages, Isfahan (Khorasgan) Branch, Islamic Azad University, Isfahan, Iran. The participants were all freshmen. 
The data from Iranian EFL learners were compared with native English data gathered through the Bergen Corpus of London Teenage Language (COLT). The Bergen Corpus of London Teenage Language (COLT) is the first extensive English Corpus focusing on the speech of teenagers. It was collected in 1993 and consisted of the spoken language of 13 to 17-year-old teenagers from different boroughs of London. The complete corpus, half a million words, has been orthographically transcribed and word-class tagged, and is a constituent of the British National Corpus.

\subsection{Data}

The data consisted of about 400 minutes of natural interactions and a few random structures co-occurring with 'please' which included 15,579 sentences made by 12 girls and eight boys. At the beginning of the course, the instructor asked the students to communicate through English in their free time (they were encouraged to communicate through the target language, which was English), including breaks between the two classes. Thus, while they were talking during the breaks, the instructor (one of the researchers) who was a Ph.D. holder in Teaching English as a Foreign Language (TEFL) recorded them via a digital recorder. Interactions were informal, and each interaction took almost 30 minutes as each break between the two classes was 30 minutes. The total thirty minutes of each break was recorded in which natural talks happened either between two students or among three or more. After the transcription of the recorded files was done by both researchers, the sentences cooccurring with 'please' were selected as the focus of the study. Only constructs that indicated impoliteness were recorded and analyzed.

It is worth noting that as there were two researchers, and they coded the data separately, substantial inter-rater reliability (IRR) was required to be obtained. Interrater reliability is a measure of the degree of agreement between the independent coding choices of two (or more) coders (Hallgren, 2012). Two raters each rated half of the data, and both raters assessed the same observations (the two raters were independent). Cohen's kappa, which is considered one of the most robust measures of IRR, was computed, and the coefficient was 0.78 , which is a substantial agreement.

\subsection{Procedure}

The students were observed during a 16-session semester, which lasted almost three months. Each session, one of the researchers had the chance to observe students for 30 minutes, where students in their free time could talk informally with each other. As the course was a 4-credit one, the students were permitted to have 30minute breaks between the two consecutive sessions. Some of the students left the class, some preferred to remain in the class, and the instructor (one of the researchers) stayed in the class, as well. When the breaks started, the students were recorded while they were talking, and they were not aware of the purpose of the study (however, we asked for their informed consent before the recording). The whole 30 
minutes were recorded, and the recordings amounted to almost 400 minutes of naturally occurring talks. In addition to the 30-minute breaks, whenever the students were asked to do the exercises, and they started to have informal personal communication, if they used structures in which please was used, the structures were immediately noted down by the instructor. The recordings were transcribed subsequently (by both researchers), and the structures in which please was used were separated, coded, and counted.

\section{Results}

\subsection{Structures co-occurring with 'please'}

After the data were transcribed, the structures co-occurring with 'please' were counted. The types and frequencies of such utterances made by Iranian teenage EFL learners and the similar data from the Bergen Corpus of London Teenage Language (COLT) are shown in Table 1:

Table 1. Raw frequency and percentages of utterance types co-occurring with 'please' made by Iranian teenage EFL learners and in the Bergen corpus of London teenage language (COLT)

\begin{tabular}{lll}
\hline Utterance type & EFL learners & COLT \\
\hline Indirect requests & $88(55.35 \%)$ & $179(48.51 \%)$ \\
Commands & $71(44.65 \%)$ & $151(40.92 \%)$ \\
Free-standing please & $0(0.00 \%)$ & $39(10.57 \%)$ \\
Total & $159(100 \%)$ & $369(100 \%)$ \\
\hline
\end{tabular}

As indicated in Table 1, indirect requests and commands were found in the informal interactions among the Iranian teenage EFL learners. While free-standing please was identified in addition to indirect requests and commands in the Bergen Corpus of London Teenage Language (COLT) data. In both EFL and English data, albeit not proportionate, indirect requests $(\mathrm{EFL}=55.35 \%$; native English $=48.51 \%)$ outnumbered the commands $(\mathrm{EFL}=44.65 \%$; native English= 40.92\%) and free-standing 'please' was the least frequent utterance type. Examples of these three structures co-occurring with 'please' are as follows:

Indirect requests:

(1)Mohammad: Your pen is beautiful.

Reza: I always have beautiful things.

Mohammad: Can you give it to me?

Reza: Noooo. Can you take your hand away please.

(2) Craig: good! When you go, don't forget me. Send me a card.

Peter: I'm not going! They just send it to me, I send it back.

Craig: Oh!

Peter: Can you get off please? Pop my microphone. 


\section{Commands:}

(3) Maryam: Oh, you don't know how ugly she had come.

Mina: Who are you talking about?

Maryam: You (laughing)

Mina: You, shut up please (laughing)

(4) Peter: In the science thing. <unclear> who is it, then.

Anthony: Cyper and Sid, with the first that came to school....

Peter: Kate, give me your pen please.

Free-standing 'please':

(5) Peter: watch with me. I wanna watch [<unclear>]

Grace: [Well], just tell them what one you want, I mean

Peter: See! I wanna see Accidental Hero.

Grace: Please.

\subsection{Functions of 'please'}

The functions behind structures with which please occurred were identified after the types of such structures were determined. Aijmer (2015) recognized seven functions in structures co-occurring with 'please' in the Bergen Corpus of London Teenage Language (COLT) data. They were verbal formula mismatches, banter or mock impoliteness, pattern-forming impoliteness, mock disputes, please expressing negative attitudes, exclamative please and emotional narratives. Whereas five functions including verbal formula mismatches, banter or mock impoliteness, patternforming impoliteness, mock disputes, and please expressing negative attitudes were found in the Iranian teenage EFL data. The frequencies and percentages of the functions of the structures co-occurring with 'please' made by Iranian teenage EFL learners are reported in Table 2 :

Table 2. Frequencies and percentages of the functions of structures co-occurring with 'please' made by Iranian teenage EFL learners

\begin{tabular}{ll}
\hline Function & Frequency (\%) \\
\hline Verbal formula mismatches & $13(8.17 \%)$ \\
Banter or mock impoliteness & $30(18.87 \%)$ \\
Pattern-forming impoliteness & $67(42.14 \%)$ \\
Mock disputes & $43(27.04 \%)$ \\
Please expressing negative attitudes & $6(3.78 \%)$ \\
\hline Total & $159(100 \%)$ \\
\hline
\end{tabular}

As can be seen in Table 2, the most frequent function was pattern-forming impoliteness followed by mock disputes, and the least frequent one was please 
expressing negative attitudes. The five functions behind the structures co-occurring with 'please' in both Iranian teenage EFL and English data are dealt with in detail below.

\subsubsection{Verbal formulae mismatches}

Verbal formulae mismatches occur when a request is accompanied by an impolite item and the term 'please' seems not to convey any politeness interpretation. Can you please and will you please are requests which co-occurred with the impolite shut up and fuck off among the Iranian EFL learners and native English speakers:

(6) Hadi: Your favorite team played badly yesterday.

Hassan: I know.

Hadi: You are a looser.

Hassan: Can you shut up please? (laugh)

Josie: Go on

Craig: Ross

Ross: No, don't. You bastards.

Craig: (laugh)

Ross: Yeah?

Craig: Will you fuck off please?

Ross: You don't even know what I said to her last night [do you?]

Craig: Fuck off.

Ross: I got you off.

In both examples, a mismatch is observed between the polite and impolite items. It is implied that in both short informal conversations, an impolite event happened, and the structures are interpersonally negative, though the politeness marker 'please' was used. However, as the conversations were informal talks between friends, the speakers were aware that their talks were not intended to be rude or aggressive. Also, despite 'Can you shut up please?' and 'Will you fuck off please?' appeared to be impolite, they were not characterized as genuine impoliteness by the speakers. Indeed, lack of politeness focuses on solidarity between the speakers.

\subsubsection{Banter or mock impoliteness}

A banter or mock impoliteness is apparently an insult, yet it is often used humorously and is not taken seriously. Thus, in the following examples, 'Show me its pictures please' and its response 'Shut up', and 'Kate, give me your pen please' and its response 'Fuck off' are related to mock impoliteness:

(8) Ali: Yesterday, we enjoyed a lot.

Mehdi: Really? Where did you go?! 
Ali: It's none of your business. (laugh)

Mehdi: Show me the pictures, then.

Ali: You, shut up please. (laugh)

Mehdi: (laugh)

(9) Peter: In the science thing. (unclear) who is it, then.

Anthony: Cyper and Sid, with the first that came to school.

Peter: Kate, give me your pen please.

Richard: Fuck off.

Peter: (laugh)

Richard: I gave you the little pen.

Peter: Who bet who?

Cassie: Today the twenty-fourth of the...

A request was made by Mehdi and Peter in informal, friendly conversations; however, the responses were not as expected. We predict that 'please' in the requests make the addressees respond positively and politely, but since they recognized the nature of the talk to be friendly, they responded rudely. The requester and the respondent laughed, and their laughter denotes that the request and its response were considered as banter, and the impolite perlocutionary act was ignored. These seemingly impolite strings were not serious and were used for teasing the addressees. Here, lack of politeness may denote that close friendship is discerned between the speakers and hearers.

\subsubsection{Pattern-forming impoliteness}

Pattern-forming impoliteness pertains to the context in which banter is stretched through a variety of turns in a conversation. The following examples demonstrate that a pattern is formed via repetition:

(10) Elham: Hurry up, give me your pen, hurry up I need it.

Zahra: I don't want.

Elham: Give it to me.

Zahra: You don't know you have to say 'please'?

Elham: Stupid, (laughing) give me your pen, please, pleeease.

(11) Peter: Give me a bit of Kit Kat. Give me a bit of Kit Kat. Can I have a bit Peter darling?

Michael: Don't you ever say please?

Peter: Please.

Michael: How rude can you get? Give me a bit of Kit Kat. How rude.

Peter: Come on fucking give some more right now. Can I have a bit please? 
As the conversation contexts were friendly, the speakers did not feel the need to use a request instead of a command, and thus the politeness marker 'please' was not added. However, the hearers made the speakers aware of the need to add 'please' and this repetition made the hearers become impolite despite the term 'please' was added. Although impoliteness items were used, laughter emphasized their friendly relations and the non-serious impoliteness. Accordingly, affection was felt rather than real impoliteness.

\subsubsection{Mock disputes}

Mock disputes involve disputes or quarrels which happen in a humorous manner. Therefore, a disagreement is seen, which is not, of course, serious. Examples of mock disputes from Iranian teenage EFL and English teenage speakers are shown below:

(12) Mohammad: His sandwiches are very delicious.

Reza: Yes, very

Mohammad: Come on, eat a bit of my sandwich.

Reza: (eating his sandwich)

Mohammad: Give me a bit of your sandwich to taste it?

Reza: I don't want.

Mohammad: You are not a human. Give me a bit please.

Reza: I can't... I mean, I don't want. (laugh)

(13) Peter: Boo (scream)

Josie: Oh, no.

Peter: Do you want not want the rest then? Let me have the rest. Can I have a tiny sip please?

Josie: No.

Peter: Please, look. I gave you some crisps (unclear).

Robert: No.

Looking at the beginning strings of the conversations in which it was implied that the speakers and the hearers were in line, the answer 'No' or 'I don't want' is not expected. The request is repeated in a few conversational turns, but disagreement is apparent and leads to impoliteness. Nonetheless, the negative answer did not convey seriousness; hence, mock can be recognized between the lines of the talks. Although the hearers' responses were not cooperative, the speakers did not take them seriously and they were just regarded as humor.

\subsection{5. 'Please' and expressing a negative attitude}

In addition to the functions explained above that mostly dealt with 'please' as an impoliteness marker, 'please' can also denote negative attitudes. Negative imperatives 
are used with 'please' and on certain occasions, and they have negative effects on the hearer as they are impolite and may express conflict. The following structures are examples of expression of negative attitude conveyed by negative imperatives and 'please':

(14) Zohre: I was in the barber's for 3 hours.

Fateme: You are kidding. (laugh)

Zohre: Believe me. I'm serious!

Fateme: You got ugly, believe me. (laugh)

Zohre: stop it... please don't mention that again.

(15) Cassie: No, I was gonna say I feel fine.

Peter: Oh! Please!

Cassie: Don't do that please. It doesn't hurt.

Peter: (laughing) Yes, it does hurt.

Cassie: (laugh)

Peter: I was right.

Craig: Alright.

Peter: I (mimicking girlie voice) choked you.

There are specific structures, including imperatives or negative imperatives, in which disagreement or disapproval is inherent, and in hearers' viewpoint, they are impolite. It seems that even if such structures are accompanied by 'please', the degree of impoliteness or the disapproval that they express is not mitigated. The term 'please' perhaps adds to the speaker's annoyance. Although 'please' could not help alleviate disapproval, laughter, in return, could compensate it; indeed, speakers and hearers' laughter indicates that the situation is not severe, and both parties take the imperatives or negative imperatives as humorous.

\section{Discussion}

This study was an attempt to shed light on the use and function of the term 'please' in Iranian teenage EFL learners' and native English teenage speakers' interactions and the difference in the use of 'please' by these two groups of speakers. The structure co-occurring with 'please' made by Iranian teenage EFL learners in informal talks were analyzed in terms of types and functions and were compared with similar data in English. The results indicated that indirect requests and commands co-occurring with please were used by both Iranian teenage EFL learners and native English teenage speakers in their friendly interactions. More specifically, indirect requests outnumbered the commands in both groups. It was worth noting that free-standing please was not observed in the Iranian teenage EFL learners' interactions. In 
addition, five functions were seen in the Iranian teenage EFL interactions: verbal formula mismatches, banter or mock impoliteness, pattern-forming impoliteness, mock disputes, and please expressing negative attitudes. In the native English teenage interactions, two more functions were found: exclamative please and emotional narratives.

Iranian teenage EFL learners and native English teenage speakers were similar in the use of indirect requests and command co-occurring with 'please'. Both groups preferred to use indirect requests more often than commands. One plausible explanation for this finding is that although the talks were friendly and commands are conceivable among friends-a command is not an indicator of power relationships - in both cultures, the teenagers were deemed to represent their equal status in their friendly talks. More often than not, commands are used as an element of power distribution. As Keating (2009) holds, when commands are used, it is implied that the hearer should comply with the one who is in a higher position. In these talks, although some learners were higher as far as English knowledge was concerned, they did not exert any power relations through avoiding using commands as much as possible.

The term 'please' as an accompanier of indirect requests and commands intends to minimize the imposition inherent in them and to show that the structure co-occurring with 'please' acts as a plea or appeal. Additionally, although in this study 'please' happened to co-occur with impolite structures which could be rude and offensive on the face of it, the addition of please to indirect request or commands denotes that the speaker does not mean to threaten the interlocutor's face. It implies that even among teenagers, the addressee is of concern not to be annoyed, but this should not be mistaken with deference. As there are no power relationships, the justification might be that respect is not a point of concern to them. Moreover, the subjects seemingly took into account how those impolite structures were used rather than what they were told. The laughter, which accompanied such structures, reduced the seriousness of context. Culpeper (2011) states that it is usual for people to be offended by how something is said to them compared to what is said to them.

So far, the term 'please', as a lexical downgrader, has been associated with politeness, and its function has been to mitigate the face-threatening content inherent in commands or requests. Thus, 'please' makes us think of it as a politeness marker. However, in the current project, it occurred with structures whose content was to insult the hearers. It was expected that 'please' save the hearers' face and it did, yet 'please' did not change the impolite structure to a polite one. As a result, 'please' can be considered an impoliteness marker in addition to its old concept as a politeness marker. Indeed, the friendly situation and the informal talk between the speakers and hearers made the impolite structures co-occurring with 'please' not offend or insult the hearers. It is implied that where such structures are used by adults or by teenagers in a formal situation, a real dispute or quarrel would be expected. 
Concerning structure types co-occurring with 'please', the point of difference between Iranian teenage EFL learners and native English teenage speakers was the absence of free-standing 'please' in the Iranian EFL data. This free-standing 'please' is highly associated with emotions, and where this structure is used, there is no request or command to be mitigated; a request or a command is hidden in it. Native English teenage speakers used free-standing 'please' in exclamatory conditions and revealed the feelings that they had at that specific moment, whereas Iranian teenage EFL learners seemed to hide their feelings. The reason behind this feeling may be twofold: 1) Iranians are not as overtly expressive as the English speakers as far as emotions are concerned, and 2) Iranians do not look overtly expressive when they use English as a foreign language; in fact, they are overtly expressive, but they do not have access to the linguistic items to express their emotions in English. These two aspects are related in a way that the first one is a pre-requisite for the second one. Although the first aspect can probably be plausible, as LeBaron (2003) also claimed that different cultures use different systems for making gestures, expressing their emotions, silence, etc., the second one sounds more sensible about Iranian teenage EFL learners. Expression of our emotions is a basic dimension of our life (Ekman, 1992), yet the ways emotions are expressed may vary from one culture to another (Eid \& Diener, 2001). Therefore, this reflects the fact that how Iranian teenage EFL learners express their emotions is acceptable to be different from how native English teenage speakers do, and thus Iranian EFL learners do not precisely know the structures that are used by native English speakers.

Given the similarities of functions behind structures co-occurring with 'please' among Iranian teenage EFL learners and native English speakers, it was found that a mismatch occurred between the impolite structures and the politeness marker 'please' among the teenagers in both cultures. This probably alludes to the fact that the boundaries between politeness and impoliteness are getting trivial for the teenagers in both cultures. Culpeper (2011) and Leech (2014) found that the overt polite and impolite meanings can come together in the same structure. Further, considering banter or mock impoliteness, pattern-forming impoliteness, mock disputes, and 'please' expressing negative attitudes, it is to be noted that seriousness was lessened during the friendly talks in both groups and thus rudeness or impoliteness was not realized as it was expected. In Culpeper's study (2011), the same results were found. This is contradictory to what we see in adults' communities in both cultures: what is an insult among adults is not an insult among teenagers.

In both groups, although a real impolite structure was used, the subjects did not get angry, upset, or disguised; in return, they laughed and continued their interactions. The possible interpretation may pertain to teenagers' mindset that is different from the adults' and a disparity in social norms: an insult is expected to lead to anger; instead, it results in laughter. Or on the other hand, the issue may not be related to mindset or general social norms for teenagers. They are using please as part of the activity they are constructing, one in which banter is important. This, of course, may emphasize the depth of relations among teenagers, too. Keeping their friendliness is 
so important to them that even if impoliteness happens, they do not take it seriously. Despite the fact that friendliness is appreciated in any culture, such behavior may create some problems in the future, and its causes are sought primarily in their parents' education and cyber-communication. Cyberspace is so wide that no one can have control over it; hence, it is evident that parents cannot teach what is right and what is wrong to their teenage children anymore. As a result, the social norms will turn out to be ambiguous for the teenagers. The outcome will be a context in which an impolite structure is accompanied by a politeness marker and changes that politeness marker into an impoliteness marker on its face.

As for the disparities found among the Iranian EFL learners and native English speakers, two functions, namely the exclamative 'please' and emotional narratives, were missing among the structures co-occurring with 'please' made by Iranian EFL learners. In the exclamative 'please', the term 'please' is usually used to intensify the emotions, for instance, the urgency of an action that is to be done, rather than a politeness marker. And, this intensification which can be achieved through repetition of 'please' is jocular rather than serious. Among Iranian EFL learners, this function was not observed perhaps because Iranians more often than not use the expression 'for the sake of God' in a similar situation. Accordingly, the absence of this function might be rooted in the differences in cultures. On some occasions, teenagers imitate others while they are talking about them and saying what they have said for humor. In such situations, the term 'please' might be applied along with mimicry. They are called emotional narratives that have a funny bearing on the hearer. Emotional narratives are found among Iranian teenagers; however, it was not present among the Iranian EFL speakers. This would be due to the issue that their informal talks occurred during the break between two classes where the instructor was present in the class as well. Power relationships and observing respect for the instructor were two inhibitory factors that students could not include mimicry in their narratives. They thus did not have emotional narratives as a function behind structures cooccurring with 'please'.

Returning to the literature, Biber et al. (1999), Bernal (2008), and De Felice and Murphy (2015) reached results that were in line with the findings of this study. Biber et al. found that 'please' can be used when emotions and attitudes are concerned, while the two latter studies pointed out that impoliteness can be fun impolite expressions that have the potential to be used humorously as banter or mock impoliteness. Moreover, they showed that in certain contexts, mocking or insulting expressions can be indicators of solidarity and intimacy. Contrary to the findings of this study, in several studies which explored English, including House (1989), Fraser (1996), Biber et al. (1999), Wichmann (2004), and Sato (2008), the term 'please' was recognized as a politeness marker accompanied by a variety of speech acts mostly requests, and it had a mitigating function. In ESL/EFL contexts, Fukushima (1990), Hill (1997), Baron (2000, 2003), and Martínez-Flor (2009) found that 'please' is used as an expression of politeness that acts to soften the imposition that is carried in commands or requests. 


\section{Conclusion}

Concerning the findings of the study, several conclusions are drawn. The main one is that indirect requests accompanied by the term 'please' outnumbered commands among both Iranian EFL learners and native English teenagers. Furthermore, freestanding 'please' that is associated with emotions was not touched by Iranian teenage EFL learners. The next conclusion pertains to the functions of 'please' in impolite structures. As the first function, 'please' is used to create or confirm a relationship that is harmonious. According to Leech (2014, p. 239), "if two or more people find it possible to exchange insults and other impolite remarks, and at the same time to treat these as non-serious or even amusing, they share a powerful way of signaling their solidarity." In young people's view, peers' impoliteness does not lead to any threat for them; thus their face is not threatened; alternatively, impoliteness enriches their friendship. Secondly, as 'mock impoliteness' seems to be amusing or entertaining; for instance, young people value entertainment skills a lot (entertainment impoliteness). Please is properly used in impoliteness context since it seems appropriate for mock politeness and banter that is entertaining and thus may establish rapport. In the end, both Iranian and English teenagers used impoliteness creatively through repetition and reformulation to create apparent rudeness and offense.

In this paper, attention was drawn to how definite politeness markers such as please can be employed to bring about opposite effects. The study suggests that we need to study explicit politeness or impoliteness formulae in a variety of contexts to realize their norms of use. Furthermore, politeness and impoliteness markers are needed to be studied in various languages to get a better understanding of their underlying structure. The main pedagogical implication of this study can be concerned with making the EFL learners aware that the term 'please' is not just a politeness marker; in certain contexts, it can change into an impoliteness marker. Additionally, EFL teachers are required to familiarize their students with a variety of functions that the term 'please' may carry to avoid miscommunications with either native English speakers or other ESL/EFL learners.

\section{The Conflict of Interest Statement}

In line with the statement of Committee on Publication Ethics (COPE), we hereby declare that we had no conflicting interests regarding any parties of this study.

\section{References}

Aijmer, K. (2009). Please: A politeness formula viewed in a translation perspective. Brno Studies in English, 35(2), 63-77.

Aijmer, K. (2015). Will you fuck off please? The use of please by London teenagers. Soprag, $3(2), 127-149$.

Andersen, G. (2001). Pragmatic markers and sociolinguistic variation. Amsterdam: John Benjamins. 
Andersson, L. M., \& Pearson, C. M. (1999). Tit for tat? The spiraling effect of incivility in the workplace. The Academy of Management Review, 24(3), 452-471.

Arundale, R. B. (2006). Face as relational and interactional: a communication framework for research on face, facework, and politeness. Journal of Politeness Research, 2(2), 193-216.

Barron, A. (2000). Acquiring 'different strokes': A longitudinal study of the development of L2 pragmatic competence. German as a Foreign Language Journal (GFL Journal), 2, 1-29.

Barron, A. (2003). Acquisition in interlanguage pragmatics: Learning how to do things with words in a study abroad context. Amsterdam: John Benjamins.

Bernal, M. (2008). Do insults always insult? Genuine politeness versus non-genuine politeness in colloquial Spanish. Pragmatics, 18(4), 775-802.

Biber, D., Johansson, S., Leech, G., Conrad, S., \& Finegan, E. (1999). Longman grammar of spoken and written English. Essex: Pearson Education Ltd.

Blum-Kulka, S., House, J., \& Kasper, G. (Eds.). (1989). Cross-cultural pragmatics: Requests and apologies. Norwood: Ablex Publishing.

Blum-Kulka, S., \& Levenston, E. A. (1987). Lexical-grammatical pragmatic indicators. Studies in Second Language Acquisition, 9(2), 155-170.

Bousfield, D. (2008). Impoliteness in interaction. Amsterdam: John Benjamins.

Bousfield, D., \& Locher, M. A. (Eds.). (2008). Impoliteness in language: Studies on its interplay with power in theory and practice. Berlin \& New York: Mouton de Gruyter.

Brown, P., \& Levinson, S. C. (1978). Universals in language usage: Politeness phenomena. In E. N. Goody (Ed.), Questions and politeness (pp. 56-310). Cambridge: Cambridge University Press.

Brown, P., \& Levinson, S. C. (1987). Politeness: Some universals in language usage. Cambridge: Cambridge University Press.

Brownell, H., \& Stringfellow, A. (1999). Making requests: illustrations of how righthemisphere brain damage can affect discourse production. Brain and Language, 68, 442 465.

Chilton, P. (1990). Politeness, politics, and diplomacy. Discourse and Society, 1(2), 201-224.

Culpeper, J. (2005). Impoliteness and entertainment in the television quiz show: The weakest link. Journal of Politeness Research, 1, 35-72.

Culpeper, J. (2011). Impoliteness: Using language to cause offence. Cambridge: Cambridge University Press.

Culpeper, J., Haugh, M., \& Kádár, D. Z. (Eds.). (2017). The Palgrave handbook of linguistic (im)politeness. London: Palgrave Macmillan.

Dalton-Puffer, Ch. (2005). Negotiating interpersonal meanings in naturalistic classroom discourse: Directives in content-and-language-integrated classrooms. Journal of Pragmatics, 37, 1275-1293.

De Felice, R., \& Murphy, M. L. (2015). The politics of please in British and American English: a corpus pragmatics approach. Abstract Book of the 8th International Corpus Linguistics Conference (CL2015), Lancaster University 21-24 July.

Economidou-Kogetsidis, M. (2005). Yes, tell me please, what time is the midday flight from Athens arriving?: Telephone service encounters and politeness. Intercultural Pragmatics, 2 , 253-273.

Eid, M., \& Diener, E. (2001). Norms for experiencing emotions in different cultures: Inter-and intra-national differences. Journal of Personality and Social Psychology, 81(5), 869-885.

Ekman, P. (1992). An argument for basic emotions. Cognition \& Emotion, 6, 169- 200.

Eelen, G. (2001). A critique of politeness theories. Manchester: St Jerome. 
Ervin-Tripp, S. (1982). Ask and it shall be given to you: Children's requests. In H. Byrnes (Ed.), Contemporary perceptions of language (pp. 235-243). Georgetown University Press: Washington, D.C.

Faerch, K., \& Kasper, G. (1989). Internal and external modification in interlanguage request realization. In S. Blum-Kulka, J. House, \& G. Kasper (Eds.), Cross-cultural pragmatics: Requests and apologies (pp. 221-247). Norwood: Ablex.

Fraser, B. (1996). Pragmatic markers. Pragmatics, 6(2), 167-190.

Fukushima, S. (1990). Offers and requests: Performance by Japanese learners of English. World Englishes, 9(3), 317-325.

Gleason, J., Perlmann, R., \& Greif, E. (1984). What's the magic word: Learning language through routines. Discourse Processes, 6, 493-502.

Grainger, K. (2018). "We're not in a club now": a neo-Brown and Levinson approach to analyzing courtroom data. Journal of Politeness Research, 14(1), 19-38.

Grice, H. P. (1975). Logic and conversation. In P. Cole, \& J. Morgan (Eds.), Syntax and Semantics 3: Speech acts (pp. 41-58). London and New York: Academic Press.

Gyasi Obeng, S. (1997). Language and politics: Indirectness in political discourse. Discourse and Society, 8(1), 49-83.

Hallgren, K. A. (2012). Computing inter-rater reliability for observational data: An overview and tutorial. Tutorials in Quantitative Methods for Psychology, 8(1), 23-34.

Haugh, M. (2007). The co-construction of politeness implicature in conversation. Journal of Pragmatics, 39(1), 84-110.

Haugh, M. (2011). Humour, face and im/politeness in getting acquainted. In B. Davies, M. Haugh, \& A. J. Merrison (Eds.), Situated politeness (pp. 165-184). London: Continuum.

Haugh M., \& Bousfield, D. (2012). Mock impoliteness, jocular mockery and jocular abuse in Australian and British English. Journal of Pragmatics, 44(9), 1099-1114.

Hill, T. (1997). The development of pragmatic competence in an EFL context (Unpublished doctoral dissertation). Temple University, Tokyo.

Holmes, J., \& Stubbe, M. (2005). Power and politeness in the workplace: A sociolinguistic analysis of talk at work. London: Longman.

Holmes, J., Marra, M., \& Vine, B. (2012). Politeness and impoliteness in ethnic varieties of New Zealand English. Journal of Pragmatics, 44(9), 1063-1076.

House, J. (1989). Politeness in English and German: The functions of Please and Bitte. In S. Blum-Kulka, J. House, \& G. Kasper (Eds.), Cross-cultural pragmatics: Requests and apologies (pp. 96-119). Norwood: Ablex.

House, J., \& Kasper, G. (1981). Politeness markers in English and German. In F. Coulmas (Ed.), Conversational routine: Explorations in standardized communication situations and prepatterned speech (pp. 157-185). The Hague: Mouton.

Keating, E. (2009). Power and pragmatics. Language and Linguistics Compass, 3(4), 996-1009.

Kecskes, I. (2017). Context-dependency and impoliteness in intercultural communication. Journal of Politeness Research, 13(1), 7-31.

Kienpointner, M. (1997). Varieties of rudeness: Types and functions of impolite utterances. Functions of Language, 4(2), 251-287.

LeBaron, M. (2003). Bridging cultural conflict: A new approach for a changing world. San Francisco: Jossey Bass.

Leech, G. (1983). Principles of pragmatics. London: Longman.

Leech, G. (2007). Politeness: Is there an East-West divide? Journal of Politeness Research, 3, 167-206. 
Leech, G. (2014). The pragmatics of politeness. Oxford: Oxford University Press.

Leech, G., \& Svartvik, J. (1975). A communicative grammar of English. London: Longman.

Lee-Wong, S. (1994). Qing/please: A polite or requestive marker? Observations from Chinese. Multilingua, 13, 343-360.

Lakoff, R. (1973). The logic of politeness; or minding your p's and q's. Chicago Linguistic Society, 9, 292-305.

Lakoff, R. (1975). Language and woman's place. Language in Society, 2(1), 45-80.

Lwanga-Lumu, C. (2002). Internal request modification by first and second language speakers. Journal for Language Teaching, 36, 289-304.

Markkanen, R. (1985). Cross-language studies in pragmatics. Jyväskylä Cross-Language Studies, 11, 65-83.

Martínez-Flor, A. (2009). The use and function of 'please' in learners' oral requestive behavior: A pragmatic analysis. Journal of English Studies, 7, 35-54.

Mullany, L. (2006). "Girls on tour": politeness, small talk, and gender in managerial business meetings. Journal of Politeness Research, 2(1), 55-77.

Níkleva, D. G. (2018). Markers of politeness and impoliteness in student-teacher interaction in the discourse genre of emails. Revista Signos. Estudios de Lingüistica, 51(97), 214-235.

Pavlidou, T. S. (2000). Between politeness and impoliteness: boys and girls in classroom interaction. Studies in Greek Linguistics, 20, 437-448.

Reiter, R. M. (2000). Linguistic politeness in Britain and Uruguay: A contrastive study of requests and apologies. Amsterdam /Philadelphia: John Benjamins Publishing

Rogers, P. S., \& Lee-Wong, S. M. (2003). Reconceptualizing politeness to accommodate dynamic tensions in subordinate-to-superior reporting. Journal of Business and Technical Communication, 17(4), 379-412.

Sato, S. (2008). Use of "please" in American and New Zealand English. Journal of Pragmatics, 40(7), 1249-1278.

Stubbs, M. (1983). Discourse analysis: The sociolinguistic analysis of natural language and culture. Oxford: Blackwell.

Taleghani-Nikazm, C. (2011). Requests and orders: A cross-linguistic study of their organization in the broader social and cultural context. In K. Aijmer \& G. Anderson (Eds.), Pragmatics of society. Berlin/New York: Mouton de Gruyter.

Tracy, K., \& Tracy, S. J. (1998). Rudeness at 911: Reconceptualizing face and face attack. Human Communication Research, 25(2), 225-251.

Trosborg, A. (1995). Interlanguage pragmatics: Requests, complaints and apologies. Berlin/New York: Mouton de Gruyter.

Van der Bom, I., \& Mills, S. (2015). A discursive approach to the analysis of politeness data. Journal of Politeness Research, 11(2), 179-206.

Watts, R. (2003). Politeness. Cambridge: Cambridge University Press.

Wichmann, A. (2005). Please - from courtesy to appeal: The role of intonation in the expression of attitudinal meaning. English Language and Linguistics, 9, 229-253.

Wichmann, A. (2004). The intonation of please-requests: A corpus-based study. Journal of Pragmatics, 36, 1521-1549.

Yamazaki, T. (2002). Learning speech acts in English: an investigation of requests made by Japanese learners of English. Pan-Pacific Association of Applied Linguistics 6, 123-137.

\section{Copyrights}

Copyright for this article is retained by the author(s), with first publication rights granted to the Journal. 
This is an open-access article distributed under the terms and conditions of the Creative Commons Attribution license (CC BY-NC-ND) (http://creativecommons.org/licenses/by-nc-nd/4.0/). 